\title{
Change in sympathetic nerve firing pattern associated with dietary weight loss in the metabolic syndrome
}

\section{Elisabeth Lambert ${ }^{1}{ }^{*}$, Nora E. Straznicky ${ }^{1}$, Tye Dawood ${ }^{2}$, Carolina Ika-Sari ${ }^{1}$, Mariee Grima ${ }^{1}$, Murray D. Esler ${ }^{1}$, Markus P. Schlaich ${ }^{3}$ and Gavin W. Lambert ${ }^{1}$}

${ }^{1}$ Human Neurotransmitters, Baker IDI Heart and Diabetes Institute, Melbourne, VIC, Australia

2 Integrative Physiology Unit, School of Medicine, University of Western Sydney, Sydney, NSW, Australia

${ }^{3}$ Neurovascular Hypertension and Kidney Disease Laboratories, Baker IDI Heart and Diabetes Institute, Melbourne, VIC, Australia

\section{Edited by:}

Jean-Pierre Montani, University of

Fribourg, Switzerland

\section{Reviewed by:}

Bruce Vanvliet, Memorial University of Newfoundland, Canada

Jens Jordan, Medical School

Hannover, Germany

*Correspondence:

Elisabeth Lambert, Human

Neurotransmitters Laboratory, Baker

IDI Heart and Diabetes Institute, PO

Box 6492 St Kilda Road Central,

Melbourne, VIC 8008, Australia.

e-mail: elisabeth.lambert@bakeridi.

edu.au
Sympathetic activation in subjects with the metabolic syndrome (MS) plays a role in the pathogenesis of cardiovascular disease development. Diet-induced weight loss decreases sympathetic outflow. However the mechanisms that account for sympathetic inhibition are not known. We sought to provide a detailed description of the sympathetic response to diet by analyzing the firing behavior of single-unit sympathetic nerve fibers. Fourteen subjects ( $57 \pm 2$ years, nine men, five females) fulfilling ATP III criteria for the MS underwent a 3-month low calorie diet. Metabolic profile, hemodynamic parameters, and multi-unit and single-unit muscle sympathetic nerve activity (MSNA, microneurography) were assessed prior to and at the end of the diet. Patients' weight dropped from $96 \pm 4$ to $88 \pm 3 \mathrm{~kg}$ $(P<0.001)$. This was associated with a decrease in systolic and diastolic blood pressure $(-12 \pm 3$ and $-5 \pm 2 \mathrm{mmHg}, P<0.05)$, and in heart rate $(-7 \pm 2 \mathrm{bpm}, P<0.01)$ and an improvement in all metabolic parameters (fasting glucose: $-0.302 .1 \pm 0.118 \mathrm{mmol} / \mathrm{l}$, total cholesterol: $-0.564 \pm 0.164 \mathrm{mmol} / \mathrm{l}$, triglycerides: $-0.414 \pm 0.137 \mathrm{mmol} / \mathrm{l}, P<0.05)$. Multiunit MSNA decreased from $68 \pm 4$ to $59 \pm 5$ bursts/100 heartbeats $(P<0.05)$. Single-unit MSNA indicated that the firing rate of individual vasoconstrictor fibers decreased from $59 \pm 10$ to $32 \pm 4$ spikes $/ 100$ heart beats $(P<0.05)$. The probability of firing decreased from $34 \pm 5$ to $23 \pm 3 \%$ of heartbeats $(P<0.05)$, and the incidence of multiple firing decreased from $14 \pm 4$ to $6 \pm 1 \%$ of heartbeats $(P<0.05)$. Cardiac and sympathetic baroreflex function were significantly improved (cardiac slope: $6.57 \pm 0.69$ to $9.57 \pm 1.20 \mathrm{~ms} \cdot \mathrm{mm} \mathrm{Hg}^{-1}$; sympathetic slope: $-3.86 \pm 0.34$ to $-5.05 \pm 0.47$ bursts $/ 100$ heartbeats $\cdot \mathrm{mmHg}^{-1}, P<0.05$ for both). Hypocaloric diet decreased sympathetic activity and improved hemodynamic and metabolic parameters. The sympathoinhibition associated with weight loss involves marked changes, not only in the rate but also in the firing pattern of active vasoconstrictive fibers.

Keywords: metabolic syndrome, sympathetic nervous system, autonomic function, diet

\section{INTRODUCTION}

Sympathetic activation is a hallmark in obesity. While uncomplicated obesity is accompanied by an increase in muscle sympathetic nerve activity (MSNA; Lambert et al., 2010b), sympathetic activation is more pronounced in obese subjects with central fat accumulation (Alvarez et al., 2002; Grassi et al., 2004), hypertension (Grassi et al., 2000; Lambert et al., 2007), obstructive sleep apnoea (Grassi et al., 2005b), and when associated with the metabolic syndrome (MS; Grassi et al., 2005a). Such sympathoexcitation is most likely involved in the generation and aggravation of the hemodynamic and metabolic profile of obese individuals as it has been shown to favor blood pressure (BP) elevation (Grassi et al., 2004), reduced insulin sensitivity and increased serum triglycerides (Landsberg, 2001) and to be associated with left ventricular hypertrophy (Schlaich et al., 2003) and dysfunction (Grassi et al., 2009). Reinforcing the possible deleterious impact of sympathetic overactivity in obesity, we recently demonstrated a direct relationship between sympathetic drive and the degree of kidney, cardiac, and endothelial dysfunction in a population of young overweight individuals prior to the development of any elevation in BP (Lambert et al., 2010b). Life style modification is the first line treatment for the management of the MS. Hence, we have demonstrated that diet-induced calorie restriction not only improved all components of the MS but also significantly lowered BP (Straznicky et al., 2005), improved renal function (Straznicky et al., 2011b), and that these improvements were underpinned by a marked decrease in multiunit MSNA activity. As such sympathoinhibition is an important goal in the therapeutic approach in the MS (Grassi, 2006; Mancia et al., 2007). Direct recording of multi-unit MSNA provides an estimation of overall sympathetic activity but does not indicate how the activation is brought about nor the mechanism by which changes in sympathetic nerve firing can occur. Indeed, different mechanisms, including recruitment of active fibers, increased probability or rate of firing of active fibers, or increased discharge (multiple firing) within a sympathetic burst can be at play (Macefield et al., 1994). We recently demonstrated that in subjects with obesity, recruitment of additional fibers was the central mechanism by which sympathoexcitation occurs because the firing rate 
of individual fiber was normal and incidence of multiple firing was rare (Lambert et al., 2007). In hypertensive subjects with the MS, we also observed that the incidence of multiple firing was linked with anxiety proneness (Lambert et al., 2010a). Therefore, recording the firing pattern of single vasoconstrictor neurons provides additional information about the mechanisms underlying the ultimate degree of sympathetic outflow. We therefore sought to determine whether the pattern of sympathoexcitation of single-unit MSNA was altered following diet-induced weight loss in subjects with the MS.

\section{MATERIALS AND METHODS}

Subjects and data were drawn from our previous investigations examining the role of diet on sympathetic nervous activity in subjects with the MS (Straznicky et al., 2005, 2011a).

The clinical trial was registered at ClinicalTrials.gov trial NCT00163943. Only patients with successful single-unit MSNA measurements obtained on two occasions (before and after the diet) were included $(n=14)$. These subjects comprised nine men and five postmenopausal women, aged 49-70 years ( mean $=57 \pm 2$ years), who fulfilled Adult Treatment Panel III criteria for the MS (Third Report of the National Cholesterol Education Program, 2002). Participants had central obesity (waist circumference $\geq 102 \mathrm{~cm}$ in men and $\geq 88 \mathrm{~cm}$ in women) and two or more MS parameters. All were non-smokers, sedentary, defined as physical exercise two or less times per week for $<20 \mathrm{~min} / \mathrm{session}$ with a stable body weight $(<1 \mathrm{~kg})$ in the previous 6 months. Exclusion criteria included type 2 diabetes (fasting glucose $\geq 7 \mathrm{mmol} / \mathrm{l}$ ), a history of secondary hypertension or cardiovascular, cerebrovascular, renal, liver, or thyroid disease, and use of drugs known to affect measured parameters. Participants treated for hypertension were studied after medications had been discontinued for at least 6 weeks. Screening investigations comprised physical examination, medical and dietary histories, 12-lead electrocardiogram, blood biochemistry, and lipid analyses. Supine BP was measured on three occasions 1 week apart as the average of five readings after a 5-min rest (Dinamap, Model 1846SX; Critikon, Tampa, FL, USA). The third of these measurements was defined as baseline BP. The study was approved by the Alfred Hospital Ethics Committee, and all subjects gave written informed consent.

\section{DIETARY PROTOCOL}

A modified Dietary Approaches to Stop Hypertension (DASH) diet was used as the background diet (Appel et al., 1997). The macronutrient composition was $30 \%$ fat (6\% polyunsaturated, $15 \%$ monounsaturated, and $9 \%$ saturated), $22 \%$ protein, and $48 \%$ carbohydrate. Basal energy requirements were calculated by indirect calorimetry (Quark b2 breath-by-breath pulmonary gas exchange analyzer; Cosmed, Rome, Italy). Energy intake was reduced by 600 calories/day. Subjects were provided with 14-day menu plans and recipes which they utilized in preparing meals in their homes. They attended the clinic fortnightly for dietary counseling. Intervention duration was 12 weeks.

\section{ANTHROPOMETRIC MEASUREMENTS}

Body weight was measured in light indoor clothes without shoes, using a digital scale. Waist circumference was measured at the midpoint between the lowest rib and iliac crest and hip circumference at the level of the greater trochanters.

\section{BIOCHEMISTRY METABOLIC MEASUREMENTS}

Fasting blood samples were drawn from a cannula placed in an antecubital vein for biochemical analysis of insulin, total cholesterol, triglycerides, HDL, LDL cholesterol, glucose, and leptin.

After resting sympathetic neural measurements were completed, a standard 75-g oral glucose tolerance test (OGTT) was performed (Glucaid, Fronine PTY, LTD., Australia). Insulin resistance was calculated from OGTT parameters according to the homeostatic model assessment (HOMA) method.

\section{ANXIETY ASSESSMENT}

Spielberger's State-Trait Anxiety Inventories (STAI) were used to assess the anxiety proneness (trait anxiety) and the situational anxiety (state anxiety) of each subject (Spielberger, 1988). This was administered immediately prior to the commencement of the investigation.

\section{Muscle sympathetic nerve activity measurements}

Multi-unit postganglionic sympathetic nerve activity was recorded using microneurography (mMSNA) in a muscle fascicle of the peroneal nerve at the fibular head. The nerve signal was amplified $(\times 50,000)$, filtered (bandpass, 700-2000 Hz), and integrated. ECG and mMSNA were digitized with a sampling frequency of $1000 \mathrm{~Hz}$ (PowerLab recording system, model ML785/8SP, AD Instruments). After an acceptable nerve-recording site was obtained, resting measurements were performed over a 20 -min period. Multi-unit muscle sympathetic nerve activity was expressed as burst frequency (bursts/min) and burst incidence (bursts/100 heart beats). The microelectrode was then manipulated until large unitary discharges appeared out of the multi-unit sympathetic bursts. Resting measurements for single-unit muscle sympathetic activity (sMSNA) were made for approximately $3 \mathrm{~min}$ at a sampling frequency of $20,000 \mathrm{~Hz}$ as previously described (Lambert et al., 2006). For the analysis of single-unit recordings, we applied similar methods as those developed by Macefield et al. (1994) which use very stringent criteria for the acceptance of a recording as being truly unitary. The morphology of every candidate spike was carefully analyzed. All spikes of similar amplitude, after allowing for the variation induced by the background noise, were selected and their shape was analyzed using computer software developed in our laboratory (Lambert et al., 2006) that allowed the superimposition of all spikes to confirm that the signals originated from a single nerve fiber (see Figure 1). Only the units satisfying these criteria were included in the analysis. For each unit the following parameters were determined:

(1) The firing rate = number of spikes occurring during the full length of the recording expressed per 100 heartbeats.

(2) Probability of firing = the percentage of heartbeats during which one or more spikes occurred (expressed as \% of heartbeats).

(3) Incidence of multiple firing $=$ percentage of heartbeats where at least 2 spikes occurred (expressed as \% of heartbeats). 


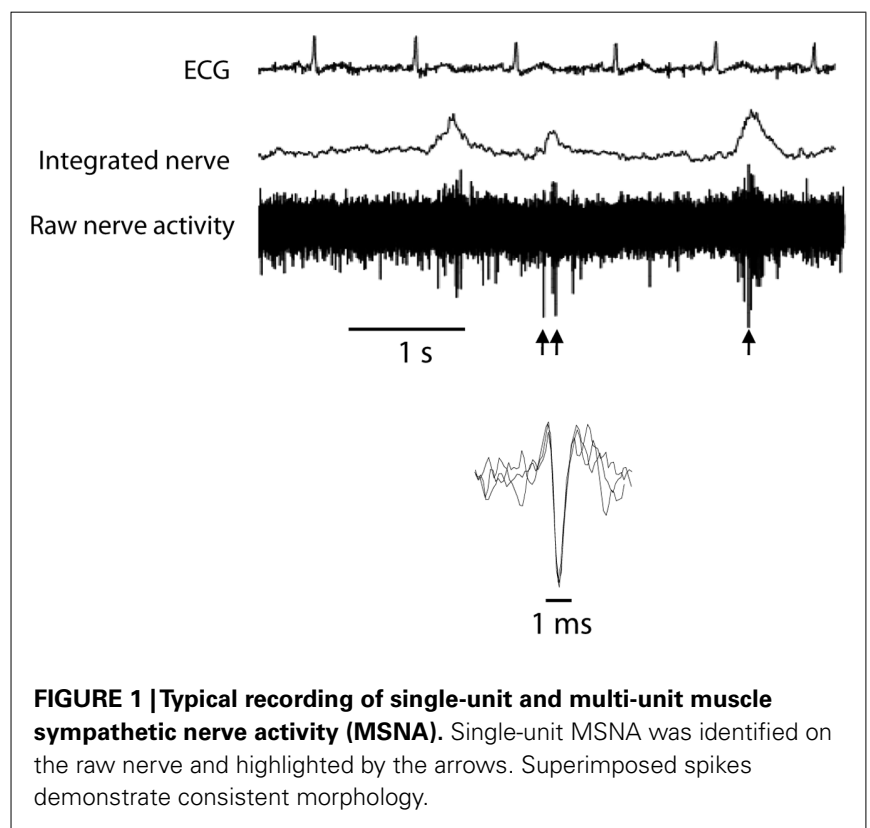

The analysis of all microneurography recordings was performed by an investigator blinded to the participant's identity and the stage of the intervention.

\section{ASSESSMENT OF SPONTANEOUS ARTERIAL BAROREFLEX CONTROL OF MSNA}

Over a 5- to 8-min resting period, diastolic blood pressures associated with individual heart beats were grouped in intervals of $2 \mathrm{mmHg}$ and, for each interval, the percentage of diastoles associated with a sympathetic burst was plotted against the mean of the pressure interval (Sundlof and Wallin, 1978). Muscle sympathetic bursts were advanced by $1.3 \mathrm{~s}$ to compensate for baroreflex delay (Fagius and Wallin, 1980). The sensitivity or sympathetic baroreflex gain was defined as the slope of the regression line and was expressed as bursts per 100 heartbeats. $\mathrm{mmHg}^{-1}$.

\section{ASSESSMENT OF SPONTANEOUS CARDIAC BAROREFLEX FUNCTION}

The sequence method of estimation of baroreflex sensitivity has been described by Parati et al. (1995). This procedure identifies the "spontaneous" sequences of three or more consecutive beats in which systolic BP progressively rose and cardiac interval progressively lengthened (type 1 sequences), or systolic BP progressively fell and cardiac interval progressively shortened (type 2 sequences), with a lag of one beat. For each sequence, the linear correlation coefficient between cardiac interval and systolic BP was computed and the sequence validated when $r>0.85$. The slope between cardiac interval and systolic $\mathrm{BP}$ was calculated for each validated sequence and expressed as $\mathrm{ms} \cdot \mathrm{mmHg}^{-1}$.

\section{STATISTICS}

Data is reported as mean $\pm \mathrm{SEM}$. A paired $t$-test was used to compare all parameters before and following the diet. Associations between variables were assessed using Pearson's correlation.
Table 1 | Anthropometric, blood pressure, metabolic, and anxiety responses to diet.

\begin{tabular}{lll}
\hline & Before diet & After diet \\
\hline BMI (kg/m²) & $33.8 \pm 1.1$ & $30.9 \pm 0.9^{* * *}$ \\
Weight (kg) & $96 \pm 4$ & $88 \pm 3^{* * *}$ \\
Waist (cm) & $108 \pm 3$ & $100 \pm 2^{* * *}$ \\
Hip (cm) & $115 \pm 2$ & $109 \pm 2^{* * *}$ \\
Waist/hip & $0.94 \pm 0.02$ & $0.92 \pm 0.02$ \\
SBP (mmHg) & $136 \pm 3$ & $124 \pm 5^{* *}$ \\
DBP (mmHg) & $77 \pm 2$ & $73 \pm 3^{*}$ \\
HR (bpm) & $68 \pm 2$ & $61 \pm 2^{* *}$ \\
Total cholesterol (mmol/l) & $5.28 \pm 0.44$ & $4.71 \pm 0.42^{* *}$ \\
LDL cholesterol (mmol/l) & $3.42 \pm 0.37$ & $3.03 \pm 0.37^{*}$ \\
HDL cholesterol (mmol/l) & $1.13 \pm 0.07$ & $1.16 \pm 0.05$ \\
Triglycerides (mmol/l) & $1.60 \pm 0.24$ & $1.19 \pm 0.21^{* *}$ \\
Fasting glucose & $5.51 \pm 0.15$ & $5.21 \pm 0.13^{*}$ \\
Fasting insulin & $11.97 \pm 1.61$ & $10.39 \pm 1.64^{*}$ \\
HOMA & $3.01 \pm 0.45$ & $2.46 \pm 0.41^{*}$ \\
Leptin (ng/ml) & $13.79 \pm 3.00$ & $9.36 \pm 2.3^{*}$ \\
State anxiety & $38 \pm 3$ & $35 \pm 3^{*}$ \\
Trait anxiety & $36 \pm 3$ & $33 \pm 2^{*}$ \\
\hline
\end{tabular}

$B M I$, body mass index; $S B P$, systolic blood pressure; $D B P$, diastolic blood pressure; HR, heart rate. ${ }^{*} P<0.05,{ }^{*} P<0.01,{ }^{*}{ }^{*} P<0.001$.

\section{RESULTS}

\section{ANTHROPOMETRIC, BLOOD PRESSURE, AND METABOLIC PROFILE}

Table 1 presents the characteristics of the participants at baseline and after the 3-months diet.

Diet induced a significant decrease in BMI, waist, and hip circumference and reduced both SBP and DBP and HR. Metabolic improvement included a decrease in total and HDL cholesterol, triglycerides, glucose, insulin levels, and HOMA index. Plasma leptin was also significantly reduced. Furthermore, participants presented with a decrease in their state and trait anxiety.

\section{SYMPATHETIC NERVOUS SYSTEM ACTIVITY AND BAROREFLEX FUNCTION \\ Muti-unit MSNA}

Following the diet, the burst frequency decreased from $45 \pm 3$ to $34 \pm 3$ bursts $/ \min (P<0.01)$ and the bursts rate from $68 \pm 4$ to $59 \pm 5$ bursts 100 heartbeats $(P<0.05$; Figure 2$)$.

\section{Single-unit MSNA}

In response to diet the firing pattern of single-unit fibers was also altered with the firing rate being decreased from $59 \pm 10$ to $32 \pm 4$ spikes $/ 100$ heart beats $(P<0.05)$, the probability of firing decreased from $34 \pm 5$ to $23 \pm 3 \%$ of heartbeats $(P<0.05)$, and the incidence of multiple firing decrease from $14 \pm 4$ to $6 \pm 1 \%$ of heartbeats $(P<0.05$; Figure 3$)$.

Cardiac and sympathetic baroreflex function were both significantly improved following the diet (Figure 4). The slope of the cardiac baroreflex increased from $6.57 \pm 0.69$ to $9.57 \pm 1.20 \mathrm{~ms} \mathrm{mmHg}^{-1} \quad(P<0.01)$ and the slope of the sympathetic baroreflex improved from $-3.86 \pm 0.34$ to $-5.05 \pm 0.47$ bursts $/ 100$ heartbeats $\cdot \mathrm{mmHg}^{-1}(P<0.05)$. 


\section{Multi-unit MSNA}
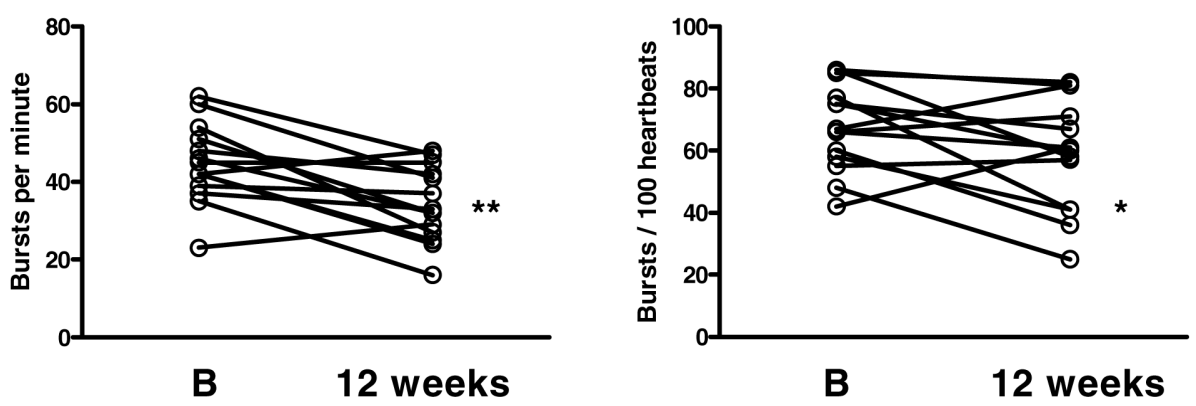

FIGURE 2 | Multi-unit muscle sympathetic nerve activity (MSNA) measured as bursts per minute and bursts per 100 heartbeats at baseline (B) and 12 weeks following the diet. ${ }^{*} P<0.05,{ }^{*} P<0.01$.

\section{Single-unit MSNA}
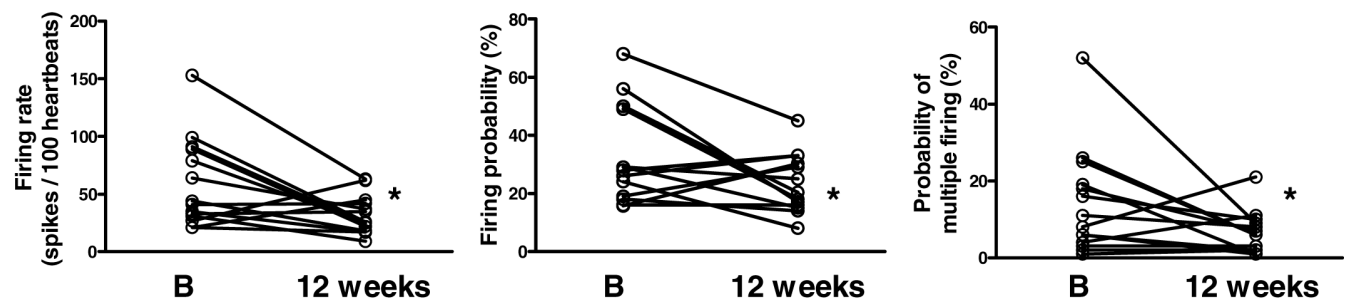

FIGURE 3 | Single-unit muscle sympathetic nerve activity (MSNA) measured as firing rate, firing probability and probability of multiple firing at baseline (B) and 12 weeks following the diet. ${ }^{*} P<0.05$.
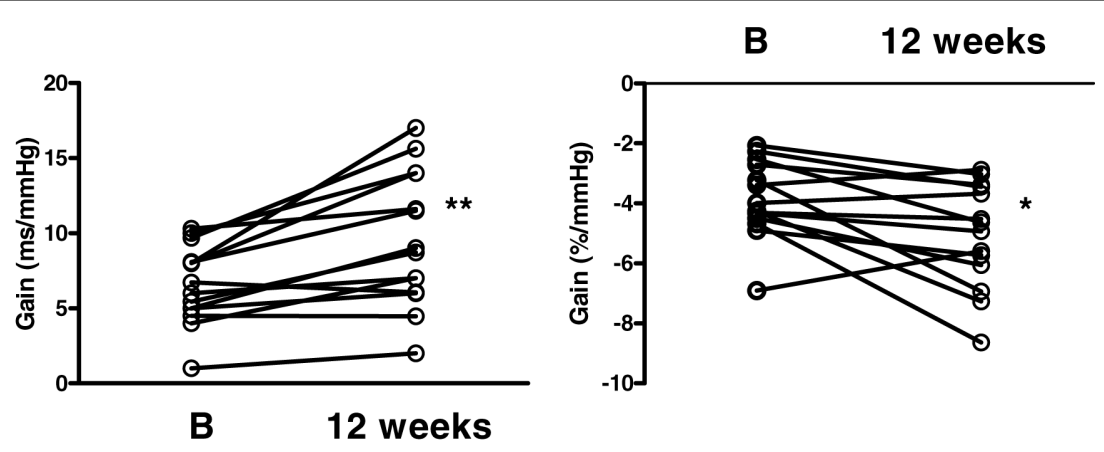

FIGURE 4 | Cardiac (left panel) and sympathetic (right panel) baroreflex function gain measured at baseline (B) and 12 weeks following the diet. ${ }^{*} P<0.05,{ }^{*} P<0.01$.

There were no significant associations between the changes in multi-unit or single-unit parameters of sympathetic nervous system activity and various hemodynamic and metabolic parameters.

\section{DISCUSSION}

We examined the effects of diet-induced weight loss on the autonomic nervous system in middle aged individuals with the MS by combining multi-unit and single-unit MSNA recordings with the assessment of cardiac and sympathetic baroreflex function. Our results indicate that in response to weight loss, along with favorable hemodynamic and metabolic changes, autonomic function is greatly improved with changes in the firing pattern of active vasoconstrictive fibers contributing to the reduction of sympathetic outflow.

The presence of sympathoexcitation in patients with the MS has previously been described (Grassi et al., 2005a; Straznicky et al., 2005). Importantly, sympathetic activation can result from 
a combination of changes in the behavior of the firing activity of individual vasoconstrictor fibers including either a change in the number of active fibers (recruitment) or/and changes in the pattern of firing such as increased firing rate and probability and increased discharge during a sympathetic burst (multiple spikes; Macefield et al., 1994). In conditions associated with elevated sympathetic outflow such as in heart failure (Macefield et al., 1999; Murai et al., 2009), essential hypertension (Greenwood et al., 1999; Lambert et al., 2007), and obstructive sleep apnoea (Elam et al., 2002), it has been shown that changes in the firing pattern contribute to the degree of sympathoexcitation. We however previously demonstrated that this is not the case in obesity where the mechanism by which sympathetic activation occurs predominantly involves recruitment of active fibers as the firing pattern of individual vasoconstrictor fibers is similar to that of non-obese individuals (Lambert et al., 2007). The characteristics of the firing pattern of sMSNA of the MS subjects in the present study were comparable to those of our previously published obese subjects (Lambert et al., 2007) indicating that sympathoexcitation in our MS participants seems to involve an increase in the recruitment of vasoconstrictor fibers rather than abnormalities in the firing pattern. Surprisingly, the present study indicates that despite a normal firing pattern, the decrease in sympathetic activity associated with weight loss involves alteration in the firing pattern of sympathetic nerves including a decrease in firing rate, probability of firing as well as a decrease in the incidence of multiple firing within a sympathetic burst. Whether changes in the firing pattern alone are sufficient to induce the observed decrease in multi-unit MSNA is not known. Given that recruitment of active fibers is the main mechanism by which sympathetic activation occurs it is likely that a decrease in the recruitment of active fibers would also contribute to the reduction in sympathetic nervous activation. Previous studies have demonstrated that changes in the firing pattern was critical in the sympathoexcitation associated with acute physiological stressors in healthy individuals (Macefield and Wallin, 1999; Murai et al., 2006) as well as in patients with chronic heart failure (Murai et al., 2009). For example Murai et al. (2009) observed that in response to handgrip exercise, heart failure patients displayed an aberrant firing pattern of individual vasoconstrictor fiber and that this most likely contributed to the exaggerated sympathoexcitation occurring during exercise. Our study extends these observations by indicating that the firing pattern of single vasoconstrictor fibers may be crucial in the adjustment of chronic sympathoinhibition associated with weight loss.

As expected, decreased sympathetic nervous activity induced by body weight loss was also associated with a number of hemodynamic, metabolic, and reflex changes suggesting that the changes in sympathetic outflow are likely to involve numerous mechanisms. Grassi et al. (1995) observed that in obese normotensive subjects the baroreceptor modulation of heart rate and MSNA was blunted and suggested a baroreflex impairment as a possible cause of the obesity-related sympathetic activation. In the present study we found that the decrease in sympathetic outflow was accompanied by a marked improvement of both cardiac and sympathetic baroreflex function which is in line of previous finding in obese normotensive subjects (Grassi et al., 1998).This suggests that the changes in sympathetic activity associated with body weight modifications may have a reflex origin and that the improvement of the baroreflex control of the cardiovascular system may lead to reduced sympathetic outflow. Single-unit vasoconstrictor neurons are known to be strongly influenced by baroreceptor stimuli within the physiological range (Macefield et al., 1994) hence, a change in baroreflex function is likely to affect their firing properties.

The improvement in the metabolic profile of our participants was significant and is likely to have played an important role in the reduction of sympathetic outflow. In particular, plasma insulin concentration and insulin resistance (HOMA) were reduced. We have previously observed that sympathetic nervous activity, as assessed from measures of whole body noradrenaline spillover and MSNA, is strongly correlated to insulin resistance in MS patients (Straznicky et al., 2005). Furthermore, reflex and metabolic mechanisms may reinforce each other in the sympatho-inhibitory effect because insulin may lead to sympathetic activation through an impairment of the baroreceptor function (Rowe et al., 1981). Sympathetic activation in turn can induce insulin resistance and hyperinsulinemia (Lembo et al., 1994). An alternative mechanism may involve changes in plasma leptin concentration which was reduced following weight loss. There exist reports indicating that leptin causes sympathoexcitation (Rahmouni, 2010). Interestingly, in this study we noted a small but significant reduction in anxiety state and trait in our participants following the weight loss intervention. Previously we demonstrated that in hypertensive patients with the MS, state and trait anxiety scores correlated with the firing rate, firing probability, and incidence of multiple firing of individual vasoconstrictor fibers but not with multi-unit MSNA indicating that a more disturbed firing pattern was associated with anxiety proneness (Lambert et al., 2010a). Our results of a simultaneous change in anxiety and firing pattern are suggestive of a potential causal effect.

The decrease in the firing probability and rate and incidence of multiple spikes associated with weight loss may have important physiological and clinical relevance. Previous reports have demonstrated that irregularity of the sympathetic firing pattern may influence effector organ responses. Indeed, irregular electrical stimulation produces faster and more pronounced vasoconstrictor responses than continuous stimulation at a regular frequency in cat skeletal muscle (Andersson et al., 1983), in small arteries and veins from rats (Nilsson et al., 1985), and in rabbit hindquarters (Ando et al., 1993). Dibona and Sawin (1999) observed that the pattern of renal sympathetic nerve stimulation in rats significantly influenced the rapidity, magnitude, and selectivity of the renal vascular and tubular responses. Furthermore we recently demonstrated that a more disturbed firing pattern of vasoconstrictor fibers to the skeletal muscle was associated with higher rates of noradrenaline spillover from the heart (Lambert et al., 2011), a finding suggesting that a more disturbed firing pattern may be associated with increased cardiovascular risk. Indeed, a direct association between left ventricular hypertrophy and the firing rate of sympathetic fibers has been shown in hypertensive individuals (Burns et al., 2007). Taken together, this observation suggests that a decrease in the firing rate and probability, and a reduction in 
incidence of multiple spikes of individual vasoconstrictor fiber may confer reduced damage to the cardiovascular and renal systems.

There are a number of limitations that we must acknowledge. The absence of a weight stable control group means that we may not have fully accounted for the effects of time and familiarization on study parameters. However sympathetic nerve recording is highly reproducible over a long period of time (Fagius and Wallin, 1993) and we previously found no time effect in sympathetic outflow in subjects with the MS (Straznicky et al., 2011a) hence the changes in sympathetic parameters are likely to be driven by the dietary restriction. The small number of subjects in our study was dictated by the technical difficulties of obtaining single-unit recordings and did not allow us to uncover possible associations between changes in single-unit parameters and other physiological characteristics. Furthermore, we cannot conclude as to whether the changes in sympathetic nerve firing properties that we observed

\section{REFERENCES}

Alvarez, G. E., Beske, S. D., Ballard, T. P., and Davy, K. P. (2002). Sympathetic neural activation in visceral obesity. Circulation 106, 2533-2536.

Andersson, P. O., Bloom, S. R., and Jarhult, J. (1983). Colonic motor and vascular responses to pelvic nerve stimulation and their relation to local peptide release in the cat. $J$. Physiol. (Lond.) 334, 293-307.

Ando, S., Imaizumi, T., and Takeshita, A. (1993). Effects of patterns of sympathetic nerve stimulation on vasoconstricting responses in the hindquarter of rabbits. J. Auton. Nerv. Syst. 45, 225-233.

Appel, L. J., Moore, T. J., Obarzanek, E., Vollmer, W. M., Svetkey, L. P., Sacks, F. M., Bray, G. A., Vogt, T. M., Cutler, J. A., Windhauser, M. M., Lin, P. H., and Karanja, N. (1997). A clinical trial of the effects of dietary patterns on blood pressure. DASH Collaborative Research Group. N. Engl. J. Med. 336, 1117-1124.

Burns, J., Sivananthan, M. U., Ball, S. G., Mackintosh, A. F., Mary, D. A., and Greenwood, J. P. (2007). Relationship between central sympathetic drive and magnetic resonance imaging-determined left ventricular mass in essential hypertension. Circulation 115, 1999-2005.

Dibona, G. F., and Sawin, L. L. (1999). Functional significance of the pattern of renal sympathetic nerve activation. Am. J. Physiol. 277, R346-R353.

Elam, M., Mckenzie, D., and Macefield, V. (2002). Mechanisms of sympathoexcitation: single-unit analysis of muscle vasoconstrictor neurons in awake OSAS subjects. J. Appl. Physiol. 93, 297-303.
Fagius, J., and Wallin, B. G. (1980). Sympathetic reflex latencies and conduction velocities in normal man. J. Neurol. Sci. 47, 433-448.

Fagius, J., and Wallin, B. G. (1993). Long-term variability and reproducibility of resting human muscle nerve sympathetic activity at rest, as reassessed after a decade. Clin. Auton. Res. 3, 201-205.

Grassi, G. (2006). Sympathetic overdrive and cardiovascular risk in the metabolic syndrome. Hypertens. Res. 29, 839-847.

Grassi, G., Dell'Oro, R., Facchini, A., Quarti Trevano, F., Bolla, G. B., and Mancia, G. (2004). Effect of central and peripheral body fat distribution on sympathetic and baroreflex function in obese normotensives. J. Hypertens. 22, 2363-2369.

Grassi, G., Dell'Oro, R., Quarti-Trevano, F., Scopelliti, F., Seravalle, G., Paleari, F., Gamba, P. L., and Mancia, G. (2005a). Neuroadrenergic and reflex abnormalities in patients with metabolic syndrome. Diabetologia 48, 1359-1365.

Grassi, G., Facchini, A., Trevano, F. Q., Dell'Oro, R., Arenare, F., Tana, F., Bolla, G., Monzani, A., Robuschi, M., and Mancia, G. (2005b). Obstructive sleep apnea-dependent and -independent adrenergic activation in obesity. Hypertension 46, 321-325.

Grassi, G., Seravalle, G., Cattaneo, B. M., Bolla, G. B., Lanfranchi, A., Colombo, M., Giannattasio, C., Brunani, A., Cavagnini, F., and Mancia, G. (1995). Sympathetic activation in obese normotensive subjects. Hypertension 25, 560-563.

are due to the weight loss or the negative energy balance. Weight loss maintenance was indeed recently shown to be associated with a rebound in mMSNA (Straznicky et al., 2011a).

In conclusion, sympathoinhibition associated with weight loss in patients with the MS involves marked changes in the firing pattern of active vasoconstrictive fibers and this may due to improved reflex mechanisms and metabolic profile.

\section{ACKNOWLEDGMENTS}

We acknowledge the contribution of Ms. Ania Schlaich in analyzing the data. Source(s) of funding: This study was supported by grants from the National Health and Research Council of Australia (NHMRC), the National Heart Foundation of Australia, and in part by the Victorian Government's Operational Infrastructure Support Program. Dr. E. Lambert, Ass. Prof. Schlaich, Prof. Esler, and Dr. G. Lambert are supported by career fellowships from the National Health and Medical research council of Australia.

Grassi, G., Seravalle, G., Colombo, M., Bolla, G., Cattaneo, B. M., Cavagnini, F., and Mancia, G. (1998). Body weight reduction, sympathetic nerve traffic, and arterial baroreflex in obese normotensive humans. Circulation 97, 2037-2042.

Grassi, G., Seravalle, G., Dell'Oro, R. Turri, C., Bolla, G. B., and Mancia, G. (2000). Adrenergic and reflex abnormalities in obesity-related hypertension. Hypertension 36, 538-542.

Grassi, G., Seravalle, G., QuartiTrevano, F., Dell'Oro, R., Arenare, F., Spaziani, D., and Mancia, G. (2009). Sympathetic and baroreflex cardiovascular control in hypertensionrelated left ventricular dysfunction. Hypertension 53, 205-209.

Greenwood, J. P., Stoker, J. B., and Mary, D. A. (1999). Single-unit sympathetic discharge: quantitative assessment in human hypertensive disease. Circulation 100, 1305-1310.

Lambert, E., Dawood, T., Straznicky, N., Sari, C., Schlaich, M., Esler, M., and Lambert, G. (2010a). Association between the sympathetic firing pattern and anxiety level in patients with the metabolic syndrome and elevated blood pressure. J. Hypertens. 28, 543-550.

Lambert, E., Sari, C. I., Dawood, T., Nguyen, J., Mcgrane, M., Eikelis, N., Chopra, R., Wong, C., Chatzivlastou, K., Head, G., Straznicky, N., Esler, M., Schlaich, M., and Lambert, G. (2010b). Sympathetic nervous system activity is associated with obesity-induced subclinical organ damage in young adults. Hypertension 56, 351-358.

Lambert, E., Hotchkin, E., Alvarenga, M., Pier, C., Richards, J., Barton, D., Dawood, T., Esler, M., and Lambert, G. (2006). Single-unit analysis of sympathetic nervous discharges in patients with panic disorder. $J$. Physiol. (Lond.) 570, 637-643.

Lambert, E., Straznicky, N., Schlaich, M., Esler, M., Dawood, T., Hotchkin, E., and Lambert, G. (2007). Differing pattern of sympathoexcitation in normal-weight and obesityrelated hypertension. Hypertension 50, 862-868.

Lambert, E. A., Schlaich, M. P., Dawood, T., Sari, C., Chopra, R., Barton, D. A., Kaye, D. M., Elam, M., Esler, M. D., and Lambert, G. W. (2011). Singleunit muscle sympathetic nervous activity and its relation to cardiac noradrenaline spillover. J. Physiol. (Lond.) 589, 2597-2605.

Landsberg, L. (2001). Insulin-mediated sympathetic stimulation: role in the pathogenesis of obesity-related hypertension (or, how insulin affects blood pressure, and why). J. Hypertens. 19, 523-528.

Lembo, G., Capaldo, B., Rendina, V., Iaccarino, G., Napoli, R., Guida, R., Trimarco, B., and Sacca, L. (1994). Acute noradrenergic activation induces insulin resistance in human skeletal muscle. Am. J. Physiol. 266, E242-E247.

Macefield, V. G., Rundqvist, B., Sverrisdottir, Y. B., Wallin, B. G., and Elam, M. (1999). Firing properties of single muscle vasoconstrictor neurons in the sympathoexcitation associated with congestive heart failure. Circulation 100, 1708-1713.

Macefield, V. G., and Wallin, B. G. (1999). Firing properties of single vasoconstrictor neurones in human subjects with high levels of muscle sympathetic activity. J. Physiol. (Lond.) 516(Pt 1), 293-301. 
Macefield, V. G., Wallin, B. G., and Vallbo, A. B. (1994). The discharge behaviour of single vasoconstrictor motoneurones in human muscle nerves. J. Physiol. (Lond.) 481(Pt 3), 799-809.

Mancia, G., Bousquet, P., Elghozi, J. L., Esler, M., Grassi, G., Julius, S., Reid, J., and Van Zwieten, P. A. (2007). The sympathetic nervous system and the metabolic syndrome. J. Hypertens. 25, 909-920.

Murai, H., Takamura, M., Maruyama, M., Nakano, M., Ikeda, T., Kobayashi, D., Otowa, K., Ootsuji, H., Okajima, M., Furusho, H., Takata, S., and Kaneko, S. (2009). Altered firing pattern of single-unit muscle sympathetic nerve activity during handgrip exercise in chronic heart failure. J. Physiol. (Lond.) 587, 2613-2622.

Murai, H., Takata, S., Maruyama, M., Nakano, M., Kobayashi, D., Otowa, K., Takamura, M., Yuasa, T., Sakagami, S., and Kaneko, S. (2006). The activity of a single muscle sympathetic vasoconstrictor nerve unit is affected by physiological stress in humans. Am. J. Physiol. Heart Circ. Physiol. 290, H853-H860.

Nilsson, H., Ljung, B., Sjoblom, N., and Wallin, B. G. (1985). The influence of the sympathetic impulse pattern on contractile responses of rat mesenteric arteries and veins. Acta Physiol. Scand. 123, 303-309.

Parati, G., Frattola, A., Di Rienzo, M., Castiglioni, P., Pedotti, A., and Mancia, G. (1995). Effects of aging on 24-h dynamic baroreceptor control of heart rate in ambulant subjects. Am. J. Physiol. 268, H1606-H1612.

Rahmouni, K. (2010). Leptin-induced sympathetic nerve activation: signaling mechanisms and cardiovascular consequences in obesity. Curr. Hypertens. Rev. 6, 104-209.

Rowe, J. W., Young, J. B., Minaker, K. L., Stevens, A. L., Pallotta, J., and Landsberg, L. (1981). Effect of insulin and glucose infusions on sympathetic nervous system activity in normal man. Diabetes 30, 219-225.

Schlaich, M. P., Kaye, D. M., Lambert, E., Sommerville, M., Socratous, F., and Esler, M. D. (2003). Relation between cardiac sympathetic activity and hypertensive left ventricular hypertrophy. Circulation 108, 560-565.

Spielberger, C. (1988). State-Trait Anger Expression Inventory: Professional Manual. Odessa: Psychological Assessment Resources.

Straznicky, N. E., Grima, M. T., Eikelis, N., Nestel, P. J., Dawood, T., Schlaich, M. P., Chopra, R., Masuo, K., Esler, M. D., Sari, C. I., Lambert, G. W., and Lambert, E. A. (2011a). The effects of weight loss versus weight loss maintenance on sympathetic nervous system activity and metabolic syndrome components. J. Clin. Endocrinol. Metab. 96, E503-E508.

Straznicky, N. E., Grima, M. T., Lambert, E. A., Eikelis, N., Dawood, T., Lambert, G. W., Nestel, P. J., Masuo, K., Sari, C. I., Chopra, R., Mariani, J. A., and Schlaich, M. P. (2011b). Exercise augments weight loss induced improvement in renal function in obese metabolic syndrome individuals. J. Hypertens. 29, 553-564.

Straznicky, N. E., Lambert, E. A., Lambert, G. W., Masuo, K., Esler, M. D., and Nestel, P. J. (2005). Effects of dietary weight loss on sympathetic activity and cardiac risk factors associated with the metabolic syndrome. J. Clin. Endocrinol. Metab. 90, 5998-6005.

Sundlof, G., and Wallin, B. G. (1978). Human muscle nerve sympathetic activity at rest. Relationship to blood pressure and age. J. Physiol. 274, 621-637.

Third Report of the National Cholesterol Education Program. (2002). Third report of the national cholesterol education program (ncep) expert panel on detection, evaluation, and treatment of high blood cholesterol in adults (Adult
Treatment Panel III) final report. Circulation 106, 3143-3421.

Conflict of Interest Statement: The authors declare that the research was conducted in the absence of any commercial or financial relationships that could be construed as a potential conflict of interest.

Received: 24 June 2011; paper pending published: 14 July 2011; accepted: 05 August 2011; published online: 26 August 2011.

Citation: Lambert E, Straznicky NE, Dawood T, Ika-Sari C, Grima $M$, Esler MD, Schlaich MP and Lambert GW (2011) Change in sympathetic nerve firing pattern associated with dietary weight loss in the metabolic syndrome. Front. Physio. 2:52. doi 10.3389/fphys.2011.00052

This article was submitted to Frontiers in Integrative Physiology, a specialty of Frontiers in Physiology.

Copyright (c) 2011 Lambert, Straznicky, Dawood, Ika-Sari, Grima, Esler, Schlaich and Lambert. This is an open-access article subject to a nonexclusive license between the authors and Frontiers Media SA, which permits use, distribution and reproduction in other forums, provided the original authors and source are credited and other Frontiers conditions are complied with. 